\title{
High maternal serum ferritin in early pregnancy and risk of spontaneous preterm birth
}

\author{
Amina Z. Khambalia ${ }^{1 *}$, Clare E. Collins ${ }^{2}$, Christine L. Roberts ${ }^{1}$, Jonathan M. Morris ${ }^{1}$, Katie L. Powell ${ }^{3}$, \\ Vitomir Tasevski ${ }^{3}$ and Natasha Nassar ${ }^{1}$ \\ ${ }^{1}$ Clinical and Population Perinatal Health Research, Kolling Institute, University of Sydney, Royal North Shore Hospital, \\ B52, St Leonards, Sydney, NSW 2065, Australia \\ ${ }^{2}$ Priority Research Centre for Physical Activity and Nutrition, Faculty of Health and Medicine, School of Health Sciences, \\ University of Newcastle, Callaghan, NSW 2308, Australia \\ ${ }^{3}$ Pathology North, NSW Health Pathology, Royal North Shore Hospital, St Leonards, NSW, Australia
}

(Submitted 19 December 2014 - Final revision received 3 May 2015 - Accepted 7 May 2015 - First published online 6 July 2015)

\section{Abstract}

Previous studies have reported inconsistent associations between maternal serum ferritin concentrations and the risk of spontaneous preterm birth (sPTB). The aim of the present study was to examine the association between Fe biomarkers, including serum ferritin concentrations, and the risk of total ( $<37$ weeks), early ( $<34$ weeks) and moderate-to-late $(34-36$ weeks) sPTB. The study cohort included 2254 women with singleton pregnancies attending first-trimester screening in New South Wales, Australia. sPTB included births following spontaneous labour or preterm premature rupture of the membranes. Serum collected at a mean gestational age of 12.0 (sD 0.9) weeks was analysed for Fe biomarkers, including serum ferritin and soluble transferrin receptor (sTfR), and the inflammatory biomarker C-reactive protein. Multivariate logistic regression analysis evaluated the association between low and high Fe levels and sPTB. Women with elevated serum ferritin concentrations were more likely to be older, nulliparous or have gestational diabetes. The multivariate analysis found increased odds of sPTB for women with elevated ferritin levels defined as $>75$ th percentile ( $\geq 43 \mu \mathrm{g} / \mathrm{l})(\mathrm{OR} 1 \cdot 49$, $95 \% \mathrm{CI}$ $1 \cdot 06,2 \cdot 10)$ and $>90$ th percentile $(\geq 68 \mu \mathrm{g} / \mathrm{l})$ (OR 1.92, 95\% CI 1.25, 2.96). Increased odds of early and moderate-to-late sPTB were associated with ferritin levels >90th percentile (OR 2.50, 95\% CI 1.32, 4.73) and >75th percentile (OR 1.56, 95\% CI 1.03, 2.37), respectively. No association was found between the risk of SPTB and elevated sTfR levels or Fe deficiency. In conclusion, elevated maternal serum ferritin levels in early pregnancy are associated with an increased risk of sPTB from 34 weeks of gestation. The usefulness of early pregnancy ferritin levels in identifying women at risk of SPTB warrants further investigation.

Key words: Iron: Ferritin: Preterm: Risk factors: Pregnancy

Preterm births continue to be the main cause of perinatal morbidity and mortality in developed countries, which increases the risk of neurocognitive and pulmonary deficits in surviving infants ${ }^{(1)}$. Spontaneous preterm birth (sPTB) of unknown aetiology accounts for $40-50 \%$ of all preterm deliveries $^{(1)}$, with the remainder attributable to maternal or fetal indications in which labour is induced or the infant is delivered by pre-labour caesarean section ${ }^{(2)}$.

The aetiology of SPTB remains elusive ${ }^{(2)}$. There is a body of evidence which suggests that infection in pregnancy may be related to preterm birth $^{(3)}$; however, the majority of randomised trials have not shown a significant reduction in preterm births following maternal administration of antibiotics ${ }^{(4)}$.
Early pregnancy factors associated with sPTB remain an important area of investigation for identifying at-risk women to study specific interventions and treatments.

The relationship between maternal Fe status and the risk of preterm delivery is uncertain ${ }^{(5)}$. Both low and elevated maternal Fe levels have been associated with the risk of preterm birth ${ }^{(6)}$. While some randomised trials of Fe supplementation in pregnancy have reported a reduction in preterm births ${ }^{(7)}$, the most recent Cochrane ${ }^{(8)}$ and systematic reviews ${ }^{(9)}$ of intervention trials have found no significant effect of Fe supplementation in pregnancy on the risk of preterm birth. In contrast, there are several observational studies that have found an association between elevated serum ferritin (a biomarker of Fe stores) in

Abbreviations: APDC, Admitted Patients Data Collection; CHeReL, Centre for Health Record Linkage; CRP, C-reactive protein; GDM, gestational diabetes mellitus; NSW, New South Wales; PPROM, preterm premature rupture of the membranes; sPTB, spontaneous preterm birth; sTfR, soluble transferrin receptor; TfR, transferrin receptor.

*Corresponding author: A. Z. Khambalia, fax +6129906 6742, email amina.khambalia@sydney.edu.au 
the second trimester and an increased risk of $\mathrm{sPTB}^{(1,10-15)}$ Potential mechanisms resulting in elevated ferritin levels being linked to the risk of SPTB include the following: intra-uterine infection; failure of the maternal plasma volume to expand; infection and inflammation ${ }^{(6)}$. Ferritin production is increased with infection and inflammation as part of the acute-phase response; therefore, interpretation of these studies is challenging. Results are conflicting, with studies differing in their definition of SPTB and in the cut-off values used for high ferritin levels $(>50 \text { th },>75 \text { th and }>90 \text { th centiles })^{(1,10-15)}$. The majority of these studies do not adjust for confounding factors, such as age and parity, and lack information on inflammatory or $\mathrm{Fe}$ biomarkers other than serum ferritin. Therefore, the aim of the present study was to examine the association between Fe biomarkers, including serum ferritin concentrations, and the risk of total, early and moderate-to-late sPTB.

\section{Subjects and methods \\ Study design and population}

The study population included women with a singleton infant with a birth weight of at least $400 \mathrm{~g}$ or at least 20 weeks of gestation, who attended first-trimester Down's syndrome screening between January and October 2007, and had results analysed by Pathology North, a state-wide public screening service in New South Wales (NSW), Australia. Serum samples that were archived and stored at $-80^{\circ} \mathrm{C}$ were thawed and used for subsequent biochemical analysis.

\section{Biochemical analysis}

Serum samples for the present study were thawed and analysed for the levels of serum ferritin $(\mu \mathrm{g} / \mathrm{l})$, soluble transferrin receptor (sTfR, nmol/l) and C-reactive protein (CRP, $\mathrm{mg} / \mathrm{dl}$ but reported as $\mathrm{mg} / \mathrm{l}$ ) using commercial assays. Serum ferritin level was measured using a solid-phase direct sandwich ELISA method (Calbiotech, Inc.) with an inter-assay CV of 6.2\%. sTfR level was measured using an ELISA method (Quantikine IVD, Human STfR Immunoassay; R\&D Systems) with an inter-assay $\mathrm{CV}$ of $6.4 \%$. CRP level was measured using the quantitative sandwich enzyme immunoassay technique (Quantikine ${ }^{\mathrm{TM}}$; R\&D Systems, Inc.) with an inter-assay CV of $13 \cdot 3 \%$.

\section{Data sources}

Laboratory records and the results of each woman's Fe biomarker analyses were linked to electronic birth and hospital records sourced from the NSW Perinatal Data Collection and the NSW Admitted Patients Data Collection (APDC), respectively, to obtain pregnancy and birth information. The Perinatal Data Collection is a statutory population-based collection of all births in NSW of at least $400 \mathrm{~g}$ birth weight or at least 20 weeks of gestation, and includes information on maternal and infant characteristics, pregnancy, labour, delivery and infant characteristics at birth. The APDC is a census of all admissions in NSW public and private hospitals. Up to fifty diagnoses for each separation are coded according to the tenth revision of the International Classification of Diseases, Australian Modification $^{(16)}$. Validation studies of the Perinatal Data Collection and the APDC have shown an excellent level of agreement with the hospital medical record and low rates of missing data $^{(17,18)}$. Reporting in both datasets has high specificity (>99\%), indicating few false positive reports. Only variables known to be reliably reported in birth and/or hospital data were included in the analysis. The NSW Centre for Health Record Linkage (CHeReL) performed probabilistic record linkage between the three datasets ${ }^{(19)}$. The CHeReL assesses linkage quality for each study, and for the present study reported $<5 / 1000$ missed links and $<2 / 1000$ false positive links. Only de-identified data were provided to the researchers. The present study was approved by the NSW Population and Health Services Research Ethics Committee (HREC/09/CIPHS/52).

\section{Variables and definitions}

The primary outcome was sPTB defined as births $<37$ weeks of gestation after the onset of spontaneous labour or preterm premature rupture of the membranes (PPROM), and subdivided into early $(<34$ weeks) and moderate-to-late (34-36) preterm births ${ }^{(2)}$. Data on serum ferritin concentrations were examined continuously and as quartiles. Low ferritin level was defined using the established definition for Fe deficiency (serum ferritin levels $<12 \mu \mathrm{g} / \mathrm{l})^{(20)}$. There is no standard cut-off value for high ferritin levels; therefore, commonly used cut-off values in the literature were assigned at the 50th, 75th and 90th percentiles ${ }^{(1,10-15)}$. As sTfR is an intercellular Fe-carrier protein, concentrations are inversely related to intracellular body Fe concentrations. Data on transferrin receptor (TfR) were examined continuously and also as $\mathrm{Fe}$ deficient (TfR levels $\geq 21 \cdot 0 \mathrm{nmol} / \mathrm{l}$ ), according to the manufacturer's guidelines, and as high $\mathrm{Fe}^{(21)}$. Again, similar to ferritin, there are not standard cut-off values for high TfR levels; therefore, cut-off values that corresponded to those used for ferritin were used for TfR ( $<50$ th, $<25$ th and $<10$ th percentiles).

Explanatory variables in the analysis included the following: maternal age; parity; gestational age and maternal body weight, both obtained at the time of blood test; country of birth; smoking during pregnancy; socio-economic status; gestational diabetes; hypertensive disorders in pregnancy. Electronic records from the laboratory database provided information on maternal body weight and gestational age at the time of screening (mean gestational age 12.0 (SD 0.9) weeks). Postcode was used to derive an indicator of socioeconomic status using an Index of Relative Disadvantage produced by the Australian Bureau of Statistics, and categorised into quintiles ${ }^{(22)}$. Hospital data were used to identify PPROM and gestational diabetes mellitus (GDM) based on diagnosis by the attending clinician ${ }^{(18,23,24)}$. Pregnancyinduced hypertensive disorders included gestational hypertension, pre-eclampsia and eclampsia in women with the onset of hypertension from 20 weeks of gestation ${ }^{(25)}$. Missing data were infrequent with the following missing records excluded from the analyses: maternal age ( $n 16$ records, $0.80 \%$ ); smoking status ( $n 11,0.55 \%$ ); country of birth ( $n 29$, $1.5 \%)$; socio-economic disadvantage ( $n$ 12, $0.60 \%$ ). 


\section{Statistical analysis}

Maternal, pregnancy, and other $\mathrm{Fe}$ and inflammatory biomarker characteristics were examined by serum ferritin quartiles, and differences were assessed using the $\chi^{2}$ test for categorical variables and the Kruskal-Wallis test for continuous variables. Post hoc comparisons between serum ferritin quartiles and explanatory variables were also made, and Bonferroni correction was used to obtain an adjusted $P$ value of 0.00125 as the cut-off for statistical significance for each of the post hoc tests. When examined continuously, serum ferritin and CRP concentrations were log-transformed. Multivariate logistic regression analysis was performed to take into account any potential confounding with explanatory variables included in the full model. Separate models were run to examine serum ferritin as a continuous variable, as quartiles, as low ferritin $(<12 \mu \mathrm{g} / \mathrm{l})$ and as high ferritin using three cut-offs ( $>50$ th, $>75$ th and $>90$ th percentiles). These cut-offs for elevated serum ferritin levels were examined to allow comparison with the cut-offs used in previous studies ${ }^{(1,10-15)}$. Separate models were also run to examine the association between SPTB and STfR treated as a continuous variable and dichotomous variables for low and high sTfR levels.

Final models were determined using backward stepwise selection, with variables of least significance progressively dropped from each model until all the remaining covariates were statistically significant (two-tailed, $P<0 \cdot 05$ ). Variables not selected were then added back into the selected model, one at a time, to assess whether they were confounders (i.e. changed the effect by more than 10\%), and the final model was determined. Statistical analysis was performed using SAS for Windows version 9.3 (SAS Institute, Inc.).

\section{Results}

A total of 2254 women with spontaneous labour or PPROM were included in the analysis. Women had a mean gestational age of 12.0 (SD 0.9) weeks at the time of blood collection. The median serum ferritin concentration for the total study population was $25 \cdot 4(25$ th -75 th $14 \cdot 5-42 \cdot 8) \mu \mathrm{g} / \mathrm{l}$. The association between quartiles of serum ferritin concentrations and maternal and pregnancy characteristics is provided in Table 1. The analyses examining the correlation between serum ferritin concentrations and maternal and pregnancy characteristics found significant correlations with maternal age $(r \quad 0.09$, $P<0.0001)$, country of birth $(r 0.04, P=0.03)$, nulliparity ( $r 0 \cdot 11, P<0 \cdot 0001)$, gestational age at blood sampling $(r-0 \cdot 04$, $P=0.05)$ and gestational diabetes $(r 0 \cdot 07, P=0 \cdot 0009)$. Very small but significant correlations were found between serum ferritin and sTfR concentrations $(r-0.05, P=0.03)$ and between serum ferritin and CRP concentrations ( $r$ 0.06, $P=0.006)$. Serum ferritin concentrations were not significantly correlated with maternal weight quintiles $(r 0.02, P=0.39)$, smoking during pregnancy $(r 0.01, P=0.65)$, socio-economic disadvantage quintiles $(r 0 \cdot 03, P=0 \cdot 10)$ and hypertensive disorders in pregnancy $(r 0.004, P=0 \cdot 86)$. Post hoc comparisons found that first serum ferritin quartile concentrations $(<15 \mu \mathrm{g} / \mathrm{l})$ were significantly more likely among younger maternal age
$(<25$ years, $P<0 \cdot 0001)$ and less likely among nulliparous women $(P<0.0001)$ and those with gestational diabetes $(P=0 \cdot 0002)$. Post hoc comparisons also found that women in the fourth serum ferritin quartile $(\geq 43 \mu \mathrm{g} / \mathrm{l})$ were more likely to have higher maternal age ( $\geq 35$ years, $P=0.0002)$ and be nulliparous $(P=0 \cdot 0002)$. None of the other tests was significant.

Relative to women with term births, women with a sPTB $<37$ weeks were more likely to be heavier $(P=0.05)$ and have GDM $(P=0.007)$ (Table 2$)$. These women also had significantly higher median concentrations of ferritin $(25 \cdot 3 v$. $26.5 \mu \mathrm{g} / \mathrm{l}, P=0.05)$ and CRP (7 v. $10 \mathrm{mg} / \mathrm{l} ; P=0.01)$. There was no difference in sTfR concentrations among women with a $\mathrm{SPTB} v$. term birth $(P=0 \cdot 61)$

The univariate analysis found significant associations between elevated serum ferritin concentrations (defined $>75$ th and $>90$ th percentiles) and sPTB (Table 3). No associations were found between elevated sTfR percentiles and sPTB, or between low Fe levels and sPTB using either serum ferritin or STfR. The multivariate analyses indicated increased odds of sPTB for serum ferritin concentrations $>75$ th percentile $(\geq 43 \mu \mathrm{g} / \mathrm{l})$ and $>90$ th percentile $(\geq 68 \mu \mathrm{g} / \mathrm{l})$ of 1.49 (95\% CI 1.06, 2.10) and 1.92 (95\% CI 1.25, 2.96), respectively (Table 3).

The univariate analysis examining the association between low and elevated serum ferritin and sTfR concentrations stratified by early and moderate-to-late sPTB is presented in online Supplementary Table S1. For early sPTB, women with serum ferritin concentrations $>90$ th percentile had a 2.54 increased odds of early sPTB (95\% CI 1.36, 4.76), and this association remained significant in the fully adjusted analyses (OR 2.50, 95\% CI 1.32, 4.73).

The univariate analysis indicated increased odds of moderate-to-late sPTB for serum ferritin concentrations $>75$ th and $>90$ th percentiles (see online Supplementary Table S1). The multivariate analysis found that women with serum ferritin concentrations $>75$ th percentile had a 1.56 increased odds of moderate-to-late sPTB (95\% CI 1.03, 2.37). The association between serum ferritin concentrations $>90$ th percentile and moderate-to-late sPTB did not reach statistical significance in the fully adjusted analyses (OR 1.62, 95\% CI 0.93, 2.84).

sTfR concentrations by specific cut-off values were not associated with increased odds of early SPTB. The significant association found between STfR and moderate-to-late sPTB in the univariate analysis (OR 1.03, 95\% CI 1.00, 1.06) was no longer significant in the fully adjusted analysis (OR 1.02, $95 \%$ CI 0.99, 1.06).

\section{Discussion}

Preterm birth is a major public health concern. The present study found that serum ferritin concentrations in early pregnancy are significantly elevated in pregnant women with subsequent spontaneous preterm labour or PPROM. We also found that women with a sPTB had significantly higher first-trimester CRP concentrations, and that there was no association between STfR concentrations (a biomarker of Fe supplied to tissues) and SPTB. These results suggest that serum ferritin levels are elevated as part of the acute-phase 
Table 1. Maternal serum ferritin quartiles by maternal and pregnancy characteristics and biochemical indices in women who had a spontaneous onset of labour or preterm premature rupture of the membranes

(Number of subjects and percentages; median values and 25th-75th percentiles)

\begin{tabular}{|c|c|c|c|c|c|c|c|c|c|}
\hline & \multicolumn{8}{|c|}{ Serum ferritin quartiles } & \multirow[b]{4}{*}{$P^{*}$} \\
\hline & \multirow{2}{*}{\multicolumn{2}{|c|}{$\begin{array}{c}<15 \mu \mathrm{g} / \mathrm{l} \\
n 580\end{array}$}} & \multirow{2}{*}{\multicolumn{2}{|c|}{$\begin{array}{c}15-24 \mu \mathrm{g} / \mathrm{l} \\
n 536\end{array}$}} & \multirow{2}{*}{\multicolumn{2}{|c|}{$\begin{array}{c}25-42 \mu \mathrm{g} / \mathrm{l} \\
n 578\end{array}$}} & \multirow{2}{*}{\multicolumn{2}{|c|}{$\frac{\geq 43 \mu \mathrm{g} / \mathrm{l}}{n 560}$}} & \\
\hline & & & & & & & & & \\
\hline & $n$ & $\%$ & $n$ & $\%$ & $n$ & $\%$ & $n$ & $\%$ & \\
\hline \multicolumn{10}{|l|}{ Maternal characteristics } \\
\hline \multicolumn{10}{|l|}{ Maternal age (years) } \\
\hline$<25$ & 78 & 13.6 & 49 & $9 \cdot 2$ & 41 & $7 \cdot 2$ & 27 & 4.9 & $<0.0001$ \\
\hline $25-34$ & 342 & 59.5 & 344 & 64.5 & 391 & 68.5 & 353 & $63 \cdot 8$ & \\
\hline$\geq 35$ & 155 & $27 \cdot 0$ & 140 & $26 \cdot 3$ & 139 & $24 \cdot 3$ & 173 & 31.3 & \\
\hline \multicolumn{10}{|l|}{ Country of birth } \\
\hline Australia & 373 & $64 \cdot 3$ & 343 & 64.0 & 362 & $62 \cdot 6$ & 344 & 61.4 & 0.88 \\
\hline New Zealand, North and South Americas & 18 & $3 \cdot 10$ & 15 & $2 \cdot 8$ & 19 & $3 \cdot 3$ & 17 & 3.0 & \\
\hline Europe & 46 & 7.9 & 30 & 5.6 & 43 & $7 \cdot 4$ & 38 & $6 \cdot 8$ & \\
\hline Middle East and Africa & 26 & 4.5 & 32 & $6 \cdot 0$ & 19 & $3 \cdot 3$ & 29 & $5 \cdot 2$ & \\
\hline South and Southeast Asia & 56 & $9 \cdot 7$ & 58 & $10 \cdot 8$ & 59 & $10 \cdot 2$ & 61 & 10.9 & \\
\hline Northeast Asia & 41 & $7 \cdot 1$ & 41 & $7 \cdot 7$ & 54 & $9 \cdot 3$ & 47 & 8.4 & \\
\hline Other & 20 & 3.5 & 17 & 3.2 & 22 & 3.8 & 24 & $4 \cdot 3$ & \\
\hline \multicolumn{10}{|l|}{ Maternal weight quintiles $(\mathrm{kg}) \dagger$} \\
\hline$<55$ & 87 & $17 \cdot 7$ & 93 & $19 \cdot 7$ & 89 & $18 \cdot 0$ & 100 & $20 \cdot 1$ & 0.04 \\
\hline $55-59$ & 106 & 21.5 & 75 & $15 \cdot 9$ & 88 & $17 \cdot 8$ & 85 & $17 \cdot 1$ & \\
\hline $60-65$ & 102 & 20.7 & 127 & $26 \cdot 9$ & 116 & $23 \cdot 4$ & 96 & $19 \cdot 3$ & \\
\hline $66-73$ & 97 & $19 \cdot 7$ & 88 & $18 \cdot 6$ & 112 & $22 \cdot 6$ & 93 & $18 \cdot 7$ & \\
\hline$\geq 74$ & 101 & 20.5 & 90 & $19 \cdot 0$ & 90 & $18 \cdot 2$ & 123 & $24 \cdot 8$ & \\
\hline Smoking during pregnancy & 39 & $6 \cdot 8$ & 31 & $5 \cdot 8$ & 44 & $7 \cdot 7$ & 35 & $6 \cdot 3$ & 0.64 \\
\hline \multicolumn{10}{|l|}{ Socio-economic disadvantage quintiles } \\
\hline 1 (most disadvantage) & 119 & 20.5 & 113 & $21 \cdot 2$ & 110 & $19 \cdot 3$ & 130 & 23.3 & 0.32 \\
\hline 2 & 115 & $19 \cdot 8$ & 84 & $15 \cdot \overline{7}$ & 99 & $17 \cdot 4$ & 91 & $16 \cdot 3$ & \\
\hline 3 & 133 & 22.9 & 126 & $23 \cdot 6$ & 116 & $20 \cdot 4$ & 107 & $19 \cdot 2$ & \\
\hline 4 & 102 & 17.6 & 111 & $20 \cdot 8$ & 115 & $20 \cdot 2$ & 116 & $20 \cdot 8$ & \\
\hline 5 (least disadvantage) & 111 & $19 \cdot 1$ & 100 & $18 \cdot 7$ & 130 & $22 \cdot 8$ & 114 & $20 \cdot 4$ & \\
\hline \multicolumn{10}{|l|}{ Pregnancy characteristics } \\
\hline Nulliparous & 268 & $46 \cdot 2$ & 292 & $54 \cdot 5$ & 315 & $54 \cdot 5$ & 340 & $60 \cdot 7$ & $<0.0001$ \\
\hline \multicolumn{10}{|l|}{ Gestational age at blood sampling (weeks) } \\
\hline $9-10$ & 41 & $12 \cdot 1$ & 36 & $11 \cdot 0$ & 52 & $14 \cdot 2$ & 64 & $16 \cdot 1$ & 0.33 \\
\hline 11 & 115 & $34 \cdot 0$ & 125 & 38.2 & 139 & 37.9 & 145 & $36 \cdot 4$ & \\
\hline $12-14$ & 182 & 53.9 & 166 & $50 \cdot 8$ & 176 & $48 \cdot 0$ & 189 & 47.5 & \\
\hline Gestational diabetes & 2 & 0.3 & 17 & 3.2 & 18 & $3 \cdot 1$ & 17 & 3.0 & 0.003 \\
\hline Hypertensive disorders in pregnancy & 23 & 4.0 & 24 & 4.5 & 17 & $2 \cdot 9$ & 25 & 4.5 & 0.51 \\
\hline \multicolumn{10}{|l|}{ Biochemical indices } \\
\hline Soluble transferrin receptor $(\mathrm{nmol} / \mathrm{l})$ & \multirow{2}{*}{\multicolumn{2}{|c|}{$15 \cdot 6$}} & & & & & & & 0.01 \\
\hline Median & & & \multicolumn{2}{|c|}{14.5} & \multicolumn{2}{|c|}{$15 \cdot 0$} & \multicolumn{2}{|c|}{$15 \cdot 3$} & \\
\hline 25th-75th percentile & \multicolumn{2}{|c|}{$12.2-19.5$} & \multicolumn{2}{|c|}{$11 \cdot 6-18 \cdot 3$} & \multicolumn{2}{|c|}{$12 \cdot 0-18 \cdot 0$} & \multicolumn{2}{|c|}{$12 \cdot 5-18.4$} & \\
\hline C-reactive protein (mg/l) & & & & & & & & & 0.13 \\
\hline Median & & & & & & & & & \\
\hline 25th-75th percentile & & & & & & & & & \\
\hline
\end{tabular}

${ }^{*} P$ values were determined by using the Kruskal-Wallis test.

† Data on maternal body weight were collected by the health care professional referring women for Down's syndrome screening.

response, and that the inflammatory process associated with sPTB is apparent from the first trimester of pregnancy.

Interestingly, the present study found that greater maternal body weight and GDM were both independently associated with elevated ferritin levels and SPTB, and thus included as confounders in the adjusted analyses. Both overweight and GDM are inflammatory conditions. While there is some evidence that maternal overweight and obesity during pregnancy is associated with increased risks of preterm birth ${ }^{(26)}$, the association between GDM and $\mathrm{SPTB}$ is inconsistent and controversial $^{(27)}$.

Results from previous studies examining the association between elevated ferritin concentrations and preterm birth have been inconsistent ${ }^{(1,10-15)}$. Only one other study has measured serum ferritin levels in the first trimester in a small sample of thirty cases and ninety controls, and found no significant difference in the proportion of women with ferritin levels $>75$ th percentile in early preterm $v$. term delivery groups $(36.7 \text { v. } 25.6 \%, P=0.251)^{(28)}$. Thresholds for elevated serum ferritin levels have varied as either $>50$ th, 75 th or 90th percentile ${ }^{(1,10-15)}$. To compare the present study with previous findings, we examined all three of these thresholds. We found that serum ferritin levels $>75$ th percentile $(\geq 43 \mu \mathrm{g} / \mathrm{l})$ were associated with increased odds of sPTB $(<37$ weeks $)$ and the subcategory moderate-to-late sPTB (34-36 weeks). However, only the higher threshold ( $>90$ th percentile) 
Table 2. Maternal characteristics, pregnancy characteristics and biochemical indices in women who had a spontaneous onset of labour or preterm premature rupture of the membranes and delivered a preterm or term infant

(Number of subjects and percentages; median values and 25th-75th percentiles)

\begin{tabular}{|c|c|c|c|c|c|}
\hline & \multicolumn{2}{|c|}{ Preterm birth ( $<37$ weeks) } & \multicolumn{2}{|c|}{ Term birth ( $\geq 37$ weeks) } & \multirow[b]{3}{*}{$P^{\star}$} \\
\hline & \multicolumn{2}{|c|}{$n 175$} & \multicolumn{2}{|c|}{ n 2079} & \\
\hline & $n$ & $\%$ & $n$ & $\%$ & \\
\hline \multicolumn{6}{|l|}{ Maternal age (years) } \\
\hline$<25$ & 16 & $9 \cdot 3$ & 179 & $8 \cdot 7$ & 0.36 \\
\hline $25-34$ & 118 & $68 \cdot 2$ & 1312 & 63.7 & \\
\hline$\geq 35$ & 39 & $22 \cdot 5$ & 568 & $27 \cdot 6$ & \\
\hline Nulliparous & 105 & $60 \cdot 0$ & 1110 & $53 \cdot 4$ & 0.09 \\
\hline \multicolumn{6}{|l|}{ Country of birth } \\
\hline Australia & 111 & 63.4 & 1311 & $63 \cdot 1$ & 0.65 \\
\hline New Zealand, North and South Americas & 6 & $3 \cdot 4$ & 63 & $3 \cdot 0$ & \\
\hline Europe & 15 & $8 \cdot 6$ & 142 & $6 \cdot 8$ & \\
\hline Middle East and Africa & 11 & $6 \cdot 3$ & 95 & $4 \cdot 6$ & \\
\hline South and Southeast Asia & 16 & $9 \cdot 1$ & 218 & $10 \cdot 5$ & \\
\hline Northeast Asia & 9 & $5 \cdot 1$ & 174 & $8 \cdot 4$ & \\
\hline Other & 7 & $4 \cdot 0$ & 76 & 3.7 & \\
\hline \multicolumn{6}{|l|}{ Gestational age at blood sampling (weeks) } \\
\hline $9-10$ & 19 & $15 \cdot 3$ & 174 & $13 \cdot 3$ & 0.72 \\
\hline 11 & 42 & $33 \cdot 9$ & 482 & $36 \cdot 9$ & \\
\hline $12-14$ & 63 & $50 \cdot 8$ & 650 & $49 \cdot 8$ & \\
\hline \multicolumn{6}{|l|}{ Maternal body weight quintiles (kg) } \\
\hline$<55$ & 27 & $17 \cdot 9$ & 342 & $18 \cdot 9$ & 0.05 \\
\hline $55-59$ & 20 & $13 \cdot 3$ & 334 & $18 \cdot 5$ & \\
\hline $60-65$ & 38 & $25 \cdot 2$ & 403 & $22 \cdot 3$ & \\
\hline $66-73$ & 23 & $15 \cdot 2$ & 367 & $20 \cdot 3$ & \\
\hline$\geq 74$ & 43 & $28 \cdot 5$ & 361 & $20 \cdot 0$ & \\
\hline Smoking during pregnancy & 14 & $8 \cdot 0$ & 135 & $6 \cdot 5$ & 0.27 \\
\hline \multicolumn{6}{|l|}{ Socio-economic disadvantage quintiles } \\
\hline 1 (most disadvantage) & 35 & $20 \cdot 0$ & 437 & $21 \cdot 1$ & 0.95 \\
\hline 2 & 30 & $17 \cdot 1$ & 359 & $17 \cdot 4$ & \\
\hline 3 & 40 & $22 \cdot 9$ & 442 & $21 \cdot 4$ & \\
\hline 4 & 32 & $18 \cdot 3$ & 412 & $19 \cdot 9$ & \\
\hline 5 (least disadvantage) & 38 & $21 \cdot 7$ & 417 & $20 \cdot 2$ & \\
\hline Gestational diabetes & 10 & $5 \cdot 7$ & 44 & $2 \cdot 1$ & 0.007 \\
\hline Hypertensive disorders in pregnancy & 11 & $6 \cdot 3$ & 78 & $3 \cdot 8$ & $0 \cdot 1$ \\
\hline Serum ferritin $(\mu \mathrm{g} / \mathrm{l})$ & & & & & 0.05 \\
\hline Median & \multicolumn{2}{|c|}{$26 \cdot 5$} & \multicolumn{2}{|c|}{$25 \cdot 3$} & \\
\hline 25th-75th percentile & \multicolumn{2}{|c|}{$16 \cdot 2-52 \cdot 3$} & \multicolumn{2}{|c|}{$14 \cdot 3-42 \cdot 1$} & \\
\hline \multicolumn{5}{|l|}{ Soluble transferrin receptor $(\mathrm{nmol} / \mathrm{l})$} & 0.61 \\
\hline Median & \multicolumn{2}{|c|}{$15 \cdot 2$} & \multicolumn{2}{|c|}{$15 \cdot 1$} & \\
\hline 25th-75th percentile & \multicolumn{2}{|c|}{$11 \cdot 9-19 \cdot 0$} & \multicolumn{2}{|c|}{$12 \cdot 1-18 \cdot 6$} & \\
\hline C-reactive protein (mg/dl) & & & & & 0.01 \\
\hline Median & \multirow{2}{*}{\multicolumn{2}{|c|}{$\begin{array}{c}1.0 \\
0.4-1.9\end{array}$}} & \multirow{2}{*}{\multicolumn{2}{|c|}{$\begin{array}{c}0.7 \\
0.3-1.5\end{array}$}} & \\
\hline 25th-75th percentile & & & & & \\
\hline
\end{tabular}

* $P$ values were determined by using the $\chi^{2}$ test.

for serum ferritin levels ( $\geq 68 \mu \mathrm{g} / \mathrm{l}$ ) was significantly associated with early sPTB in the present study. This is in agreement with a few studies that have found levels $>30 \mu \mathrm{g} / \mathrm{l}$ to be associated with preterm birth ${ }^{(11,14)}$. Inconsistent findings across studies may be related to differences in study populations and the severity of SPTB, reduced numbers of women in certain categories of exposure and/or outcome, and the types of confounders included in adjusted analyses. Previous studies have mostly been cross-sectional and limited to serum ferritin measurements later in pregnancy or at the time of birth $^{(10,11,13-15)}$.

The usefulness of serum ferritin as a marker for sPTB is uncertain. Significant associations between elevated ferritin concentrations and sPTB were not found across all the thresholds or subtypes for sPTB (i.e. early $v$. moderateto-late). Before routine screening of serum ferritin for the prediction of SPTB can be recommended, further research is needed to establish normative values, to understand the variability in ferritin as an early pregnancy biomarker, and to determine its accuracy, reliability, interpretability and feasibility. While the present study found increased odds of sPTB in association with elevated ferritin concentrations, this does not demonstrate that ferritin will function well as a diagnostic test unless ferritin is shown to be a manifestation of $\mathrm{sPTB}^{(29)}$. Although significant, the overall difference observed in median ferritin concentrations was minimal between women with and without SPTB. Further research is needed to validate our findings in other study populations. 
Table 3. First-trimester serum ferritin and soluble transferrin receptor concentrations in women who had a spontaneous onset of labour or preterm premature rupture of the membranes and delivered a preterm $v$. a term infant

(Number of subjects and percentages; odds ratios and $95 \%$ confidence intervals; median values and 25th-75th percentiles)

\begin{tabular}{|c|c|c|c|c|c|c|c|c|}
\hline & \multicolumn{2}{|c|}{$\begin{array}{l}\text { Preterm birth } \\
\text { (<37 weeks) }\end{array}$} & \multicolumn{2}{|c|}{$\begin{array}{c}\text { Term birth } \\
\text { ( } \geq 37 \text { weeks) }\end{array}$} & \multirow{2}{*}{$\begin{array}{c}\text { Unadjusted } \\
\text { OR }\end{array}$} & \multirow[b]{2}{*}{$95 \% \mathrm{Cl}$} & \multirow{2}{*}{$\begin{array}{c}\text { Adjusted } \\
\text { OR }^{\star}\end{array}$} & \multirow[b]{2}{*}{$95 \% \mathrm{Cl}$} \\
\hline & $n$ & $\%$ & $n$ & $\%$ & & & & \\
\hline \multicolumn{9}{|l|}{ Serum ferritin $(\mu \mathrm{g} / \mathrm{l})$} \\
\hline Median & \multicolumn{2}{|c|}{26.5} & \multicolumn{2}{|c|}{$25 \cdot 3$} & \multirow{2}{*}{\multicolumn{2}{|c|}{$1 \cdot 24 \dagger$}} & \multicolumn{2}{|c|}{$1 \cdot 17$} \\
\hline 25th-75th percentile & \multicolumn{2}{|c|}{$16 \cdot 2-52 \cdot 3$} & \multicolumn{2}{|c|}{$14 \cdot 3-42 \cdot 1$} & $1.02-1.50$ & & \multicolumn{2}{|c|}{$0.96-1.43$} \\
\hline \multicolumn{9}{|l|}{ Soluble transferrin receptor $(\mathrm{nmol} / \mathrm{l})$} \\
\hline Median & \multirow{2}{*}{\multicolumn{2}{|c|}{$\begin{array}{c}15 \cdot 2 \\
11 \cdot 9-19 \cdot 0\end{array}$}} & \multirow{2}{*}{\multicolumn{2}{|c|}{$\begin{array}{c}15 \cdot 1 \\
12 \cdot 1-18 \cdot 6\end{array}$}} & \multirow{2}{*}{\multicolumn{2}{|c|}{$\begin{array}{c}1.02 \\
0.99-1.04\end{array}$}} & \multirow{2}{*}{\multicolumn{2}{|c|}{$\begin{array}{c}1.01 \\
0.99-1.04\end{array}$}} \\
\hline 25th-75th percentile & & & & & & & & \\
\hline \multicolumn{9}{|l|}{ Elevated Fe } \\
\hline \multicolumn{9}{|l|}{ High serum ferritin levels $(\mu \mathrm{g} / \mathrm{l})$} \\
\hline$>50$ th percentile $(\geq 25 \mu \mathrm{g} / \mathrm{l})$ & 95 & $54 \cdot 3$ & 1043 & $50 \cdot 2$ & 1.18 & $0.87,1.61$ & & \\
\hline$>75$ th percentile $(\geq 43 \mu \mathrm{g} / \mathrm{l})$ & 58 & 33.1 & 502 & $24 \cdot 2$ & $1.56 \dagger$ & $1 \cdot 12,2 \cdot 17$ & $1.49 \dagger$ & $1 \cdot 06,2 \cdot 10$ \\
\hline$>90$ th percentile $(\geq 68 \mu \mathrm{g} / \mathrm{l})$ & 30 & $17 \cdot 1$ & 193 & $9 \cdot 3$ & $2.02 \dagger$ & $1.33,3.08$ & $1.92 \dagger$ & $1.25,2.96$ \\
\hline \multicolumn{9}{|l|}{ Low sTfR levels (nmol/l) } \\
\hline$<50$ th percentile $(\leq 15 \mathrm{nmol} / \mathrm{l})$ & 96 & 54.9 & 1202 & $57 \cdot 8$ & 0.89 & $0.65,1.21$ & & \\
\hline$<25$ th percentile $(\leq 12 \mathrm{nmol} / \mathrm{l})$ & 50 & $28 \cdot 6$ & 663 & 31.9 & 0.85 & $0.61,1.20$ & & \\
\hline$<$ 10th percentile $(\leq 9 \mathrm{nmol} / \mathrm{l})$ & 24 & $13 \cdot 7$ & 221 & $10 \cdot 6$ & 1.34 & $0 \cdot 85,2 \cdot 10$ & & \\
\hline \multicolumn{9}{|l|}{ Fe deficiency } \\
\hline Serum ferritin $(<12 \mu \mathrm{g} / \mathrm{l})$ & 30 & $17 \cdot 1$ & 402 & $19 \cdot 3$ & 0.86 & $0.57,1.30$ & & \\
\hline $\mathrm{sTfR}(\geq 21 \mathrm{nmol} / \mathrm{l})$ & 29 & $16 \cdot 6$ & 318 & $15 \cdot 3$ & $1 \cdot 10$ & $0.73,1.67$ & & \\
\hline
\end{tabular}

sTfR, soluble transferrin receptor.

${ }^{*}$ Adjusted for maternal age, parity, gestational diabetes mellitus and C-reactive protein. Empty cells indicate that adjusted analyses were not performed due to no association being found in the univariate analysis.

$\dagger P<0.05$

It has been proposed that high ferritin concentrations may be a marker of clinical and subclinical vaginal infection, which, in turn, may be triggers in the preterm delivery pathway ${ }^{(10,13)}$. There is evidence of an association between vaginal infections and preterm delivery from longitudinal studies ${ }^{(29,30)}$ and a single randomised controlled trial which found that second-trimester antenatal screening and treatment for asymptomatic vaginal infections reduced the rate of preterm births by $50 \%{ }^{(31)}$. The association between maternal Fe status and vaginal infections in early pregnancy has not been well studied. Studies have observed an increase in various bacterial and non-bacterial infectious diseases in genetic Fe-overload diseases, such as haemochromatosis, where Fe levels in serum are increased. Given that a notable adaptation of bacterial growth is enhanced virulence secondary to acquiring a supply of Fe from the host ${ }^{(32)}$, future studies are needed to examine the relationship between maternal Fe status and early pregnancy infections.

The strengths of the present study include a longitudinal design; one of the largest sample sizes to date, with measurement of serum ferritin concentrations in the first trimester of pregnancy as well as other Fe and inflammatory biomarkers; adjustment for confounders; and a sensitivity analysis using a range of cut-off values for elevated serum ferritin concentrations. While the present study used multiple data sources to analyse serum biomarkers and a range of maternal and pregnancy characteristics, limitations include the lack of data on medical conditions that has an impact on Fe status, such as haemochromatosis, maternal characteristics associated with sPTB, such as ethnicity and BMI, as well as early pregnancy infections and placental Fe biomarkers, such as serum placental isoferritin. There is a paucity of studies on pre-pregnancy BMI for this outcome, especially for moderate and very early preterm birth. Although we only had information on maternal weight, we did find a trend towards increased SPTB with increasing maternal weight. A recent systematic review and meta-analysis has found that being overweight or slightly obese was not associated with the overall risk of preterm birth ( $<37$ weeks of gestation), but that high maternal BMI may have different effects on different subtypes of preterm birth. A notable limitation is the lack of $\mathrm{Hb}$ data, which is routinely performed during pregnancy but collected by various individual health care providers and local laboratories. There is some evidence of a U-shaped relationship between $\mathrm{Hb}$ concentrations in early pregnancy and the risk of preterm birth; however, the role of maternal $\mathrm{Hb}$ in preterm birth remains poorly defined. Another study limitation is the generalisability of the present study population, which does not represent the total state maternity population during the same period, possibly due to a healthier and more affluent group attending first-trimester screening.

In summary, results from the present study provide further support of an association between elevated ferritin concentrations in early pregnancy and the risk of sPTB. Importantly, this suggests that an inflammatory process that is detectable in early pregnancy may be a plausible biological mechanism for this association. Further research investigating the pathophysiological processes between elevated ferritin concentrations and the risk of SPTB, which considers the associations between inflammation, obesity, GDM and vaginal infections, is warranted. 


\section{Supplementary material}

To view supplementary material for this article, please visit http://dx.doi.org/10.1017/S0007114515001932

\section{Acknowledgements}

The authors thank the NSW PaLMS Pathology service and Ministry of Health for provision of the population data and the NSW CHeReL for record linkage.

The present study was funded by a National Health and Medical Research Council (NHMRC) Project Grant (no. 632653). A. Z. K. was funded by an Australian NHMRC Centers for Research Excellence (APP1001066), N. N. by a NHMRC Career Development Fellowship (no. APP1067066) and C. L. R. by a NHMRC Senior Research Fellowship (no. APP1021025). C. E. C. was supported by a Faculty of Health and Medicine Strategic Research Fellowship at University of Newcastle.

The author's contributions are as follows: A. Z. K., C. E. C., C. L. R., J. M. and N. N. conceived and designed the study; C. L. R., J. M., K. P., V. T. and N. N. acquired the data; A. Z. K. was responsible for the integrity of the data and statistical analysis; A. Z. K. drafted the manuscript. All authors critically reviewed the manuscript for important intellectual content and approved the final version of the manuscript.

None of the authors has a conflict of interest to declare.

\section{References}

1. Wen S, Smith G, Yang Q, et al. (2004) Epidemiology of preterm birth and neonatal outcome. Semin Fetal Neonatal Med 9, 429-435.

2. Goldenberg R, Culhane JF, Iams JD, et al. (2008) Epidemiology and causes of preterm birth. Lancet 371, 75-84.

3. Goldenberg R, Hauth JC \& Andrews WW (2000) Intrauterine infection and preterm delivery. N Engl J Med 342, 1500-1507.

4. McDonald H, Brocklehurst P, Parsons J, et al. (2003) Antibiotics for treating bacterial vaginosis in pregnancy. The Cochrane Database of Systematic Review 2003, issue 2, CD000262.

5. Allen L (2001) Biological mechanisms that might underlie iron's effects on fetal growth and preterm birth. $J$ Nutr 131, 581S-589S.

6. Scholl T (2005) Iron status during pregnancy: setting the stage for mother and infant. Am J Clin Nutr 81, S1218-S1222.

7. Allen L (2000) Anemia and iron deficiency: effects on pregnancy outcome. Am J Clin Nutr 71, 1280S-1284S.

8. Pena-Rosas J \& Viteri FE (2009) Effects and safety of preventive oral iron or iron and folic acid supplementation for women during pregnancy. The Cochrane Database of Systematic Review 2009, issue 4, CD004736.

9. Haider B, Olofin I, Wang M, et al. (2013) Anaemia, prenatal iron use, and risk of adverse pregnancy outcomes: systematic review and meta-analysis. BMJ 346, 3443.

10. Goldenbergm R, Tamura T, DuBard M, et al. (1996) Plasma ferritin and pregnancy outcome. Am J Obstet Gynecol $\mathbf{1 7 5}$, 1356-1359.

11. Saha C, Jain V, Gupta I, et al. (2000) Serum ferritin level as a marker of preterm labor. Int J Gynaecol Obstet 71, 107-111.

12. Scholl T (1998) High third-trimester ferritin concentration: associations with very preterm delivery, infection, and maternal nutritional status. Obstet Gynecol 92, 161-166.
13. Tamura T, Goldenberg RL, Johnston KE, et al. (1996) Serum ferritin: a predictor of early spontaneous preterm delivery. Obstet Gynecol 87, 360-365.

14. Weintraub A, Sheiner E, Mazor M, et al. (2005) Maternal serum ferritin concentration in patients with preterm labor and intact membranes. J Matern Fetal Neonatal Med 18, 163-166.

15. Xiao R, Sorensen TK, Frederick IO, et al. (2002) Maternal second-trimester serum ferritin concentrations and subsequent risk of preterm delivery. Paediatr Perinat Epidemiol 16, 297-304.

16. National Centre for Classification in Health (2004) Australian Coding Standards for ICD-1O-AM and ACHI, 5th ed. Sydney: National Centre for Classification in Health, University of Sydney.

17. Roberts C, Cameron CA, Bell JC, et al. (2008) Measuring maternal morbidity in routinely collected health data: development and validation of a maternal morbidity outcome indicator. Med Care 46, 786-794.

18. Taylor L, Travis S, Pym M, et al. (2005) How useful are hospital morbidity data for monitoring conditions occurring in the perinatal period? Aust N Z J Obstet Gynaecol 45, 36-41.

19. Lawrence G, Dinh I \& Taylor L (2008) The centre for health record linkage: a new resource for health services research and evaluation. Health Information Manage J 37, 60-62.

20. World Health Organization (WHO) (2011) Serum Ferritin Concentrations for the Assessment of Iron Status and Iron Deficiency in Populations. Vitamin and Mineral Nutrition Information System. Geneva: World Health Organization (WHO/NMH/NHD/MNM/112). http://www.who.int/vmnis/ indicators/serum_ferritin.pdf (accessed 08/01/2014).

21. Human sTfR Immunoassay Quantikine IVD Soluble Transferin Receptor (2013) ELISA R\&D Systems, Inc. Catalog no. DTFR1. R\&D Systems Minneapolis, USA. Co. Ltd.

22. Australian Bureau of Statistics (2008) Socio-economic indexes for areas (SEIFA), technical paper. 2039, 0.55 .00

23. Bell J, Ford JB, Cameron CA, et al. (2008) The accuracy of population health data for monitoring trends and outcomes among women with diabetes in pregnancy. Diabetes Res Clin Pract 81, 105-109.

24. Lain S, Hadfield RM, Raynes-Greenow CH, et al. (2002) Quality of data in perinatal population health databases: a systematic review. Med Care 50, e7-e20.

25. Brown M, Lindheimer MD, de Swiet M, et al. (2001) The classification and diagnosis of the hypertensive disorders of pregnancy: statement from the International Society for the Study of Hypertension in Pregnancy (ISSHP). Hypertens Pregnancy 20, IX-XIV.

26. Cnattingius S, Villamor E, Johansson S, et al. (2013) Maternal obesity and risk of preterm delivery. JAMA 309, 2362-2370.

27. Yogev Y \& Langer O (2007) Spontaneous preterm delivery and gestational diabetes: the impact of glycemic control. Arch Gynecol Obstet 276, 361-365.

28. Beta J, Poon LC, Bakalis S, et al. (2012) Maternal serum ferritin at 11- to 13-week gestation in spontaneous early preterm delivery. J Matern Fetal Neonatal Med 10, 1852-1855.

29. Mayeux R (2004) Biomarkers: potential uses and limitations. NeuroRx 1, 182-188.

30. Hay P, Lamont RF, Taylor-Robinson D, et al. (1994) Abnormal bacterial colonisation of the genital tract and subsequent preterm delivery and late miscarriage. BMJ 308, 295-298.

31. Kiss H, Petricevic L \& Husslein P (2004) Prospective randomised controlled trial of an infection screening programme to reduce the rate of preterm delivery. BMJ 329, 371.

32. Khan F, Fisher MA \& Khakoo RA (2007) Association of hemochromatosis with infectious diseases: expanding spectrum. Int J Infect Dis 11, 4872-4877. 